\title{
Effects of rainfall data resolution on watershed-scale model performance in predicting runoff
}

\author{
Huiliang Wang, Xuyong Li and Shaonan Hao
}

\begin{abstract}
The hydrologic simulation program-FORTRAN (HSPF) model is widely used to develop management strategies for water resources, but its effectiveness is limited by predictive uncertainties associated with model input data. This study evaluated the effect of rainfall data resolution on the model performance when predicting runoff. We examined hourly, 3-hourly, 12-hourly, and 24-hourly temporal resolutions, and spatial resolutions from seven to one rain gauges. We used a statistical sensitivity analysis to test the effect of resolution on model accuracy, and a dynamic sensitivity analysis to test the effect on model parameters. Our results indicate that the model performance reduces when using a coarser rainfall resolution. The model used the corresponding parameters to absorb the effect of various resolution changes and reduced their impact on the runoff simulations. We used the paired-samples $t$-test to examine the significance of the rainfall data resolution to the model parameters, which revealed that the model accuracy was more sensitive to the temporal resolution. Our statistical analysis of the dispersion examined the parameter values. It showed that one parameter was sensitive to temporal resolution and three parameters were sensitive to spatial resolution. This study provided useful information for determining HSPF model parameters using rainfall data at different resolutions.
\end{abstract}

Key words | HSPF model, model performance, rainfall data, spatial resolution, temporal resolution

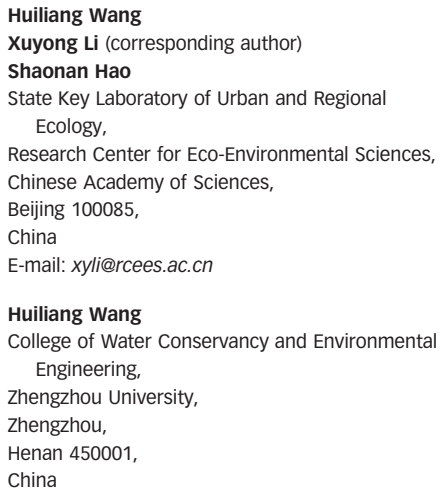

\section{INTRODUCTION}

Hydrologic models have been used to examine watershedscale processes and evaluate the hydrologic effects of various management scenarios (Beven 200I; Pechlivanidis et al. 20II). Rainfall is the primary input to most hydrological systems, and most studies have shown that accurate rainfall data are crucial to the model's accuracy and subsequent river basin management. It has been reported that the accuracies of models are significantly influenced by the spatial variability of rainfall, and the random or systematic errors in rainfall data (Duncan et al. I993; Xu \& Vandewiele I994; Paturel et al. I995; Oudin et al. 2006; Adams et al. 20I2). Recently, studies have investigated the impacts of temporal and spatial rainfall data on the accuracy and parameters of a watershed model (Mohamoud \& Lourdes 20I2). The temporal and spatial resolution of rainfall data are critical elements for large watersheds, and high doi: $10.2166 /$ wcc. 2014.153 resolution data are rarely available. This seems to be particularly true in China and some African countries, because their data sharing systems are imperfect.

Rainfall data resolution can affect the accuracy and parameter estimation (PEST) of watershed models during the calibration and validation processes. The effects on model accuracy have been extensively investigated over the past few decades (Krajewski et al. I991; Finnerty et al. I997; Sun et al. 2000; Segond et al. 2007; Pechlivanidis et al. 20Io). However, the relative disparity of the results is puzzling. For example, some studies reported that runoff hydrograph predictions were improved by a higher spatial rainfall resolution (Sun et al. 2000; Pechlivanidis et al. 20Io). Others reported that the models were improved by a higher temporal resolution (Krajewski et al. I99I). Recently, Mohamoud \& Lourdes (20I2) proposed that there was an 
interaction between the temporal and spatial resolutions of rainfall, and the model was more sensitive to spatial resolution than temporal resolution. Some studies investigating these effects on the model parameters have been reported (Aronica et al. 2005; Littleood \& Croke 2008, 2013; Wang et al. 2009). Among these studies, Littleood \& Croke (2008) concluded that the model accuracy was not significantly affected by the temporal resolution, but the values of the calibrated model parameters were very sensitive to the temporal resolution. Wang et al. (2009) concluded that the parameter values are influenced by the temporal resolution of the calculation and the rainfall intensity-duration relationship. However, there are some intriguing differences in the results of analyses of a very small number of quite different catchments using different parameter calibration schemes and event-related confounding factors (Littlewood et al. 20II). Therefore, it is difficult for us to determine the extent of the effect of data resolution on the parameters determined during the model calibration process. However, most previous studies did not investigate the combined impacts of both temporal and spatial input data resolution. We must investigate the effects of the temporal and spatial resolution on the model accuracy and parameters to provide a systematic assessment of the impacts. A lack of agreement on the effect of rainfall resolution on the predictive performance may indicate that there is no consensus concerning the extent of the effects of the temporal and spatial resolution of rainfall data.

Thus, there were two aims to this work. First, we wished to provide hydrologists with an overview of the influences of rainfall data resolution on watershed-scale model accuracy and parameters. Second, we have developed comparative statistics that can describe the effects of rainfall data on runoff, particularly examining the effects on the model accuracy and parameters. The following questions are addressed:

(1) Is the model accuracy more sensitive to temporal resolution or spatial resolution?

(2) What are the differences in the model parameters for different temporal and spatial rainfall resolutions?

\section{MATERIALS AND METHODS}

\section{Study area}

The Yixun River basin covers approximately $6,700 \mathrm{~km}^{2}$ and is a tributary of the Luan River, which is located in the northeast of China (Figure 1). This watershed is a typical

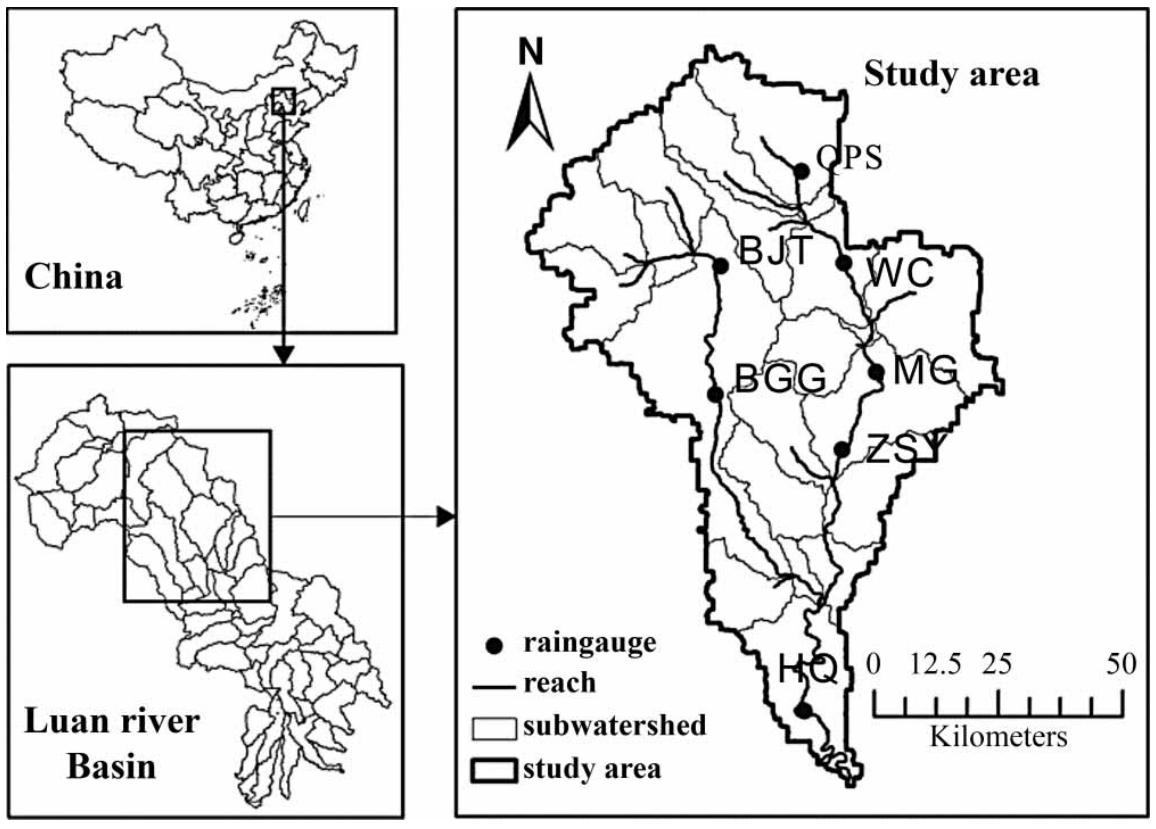

Figure 1 | Study area, Hebei province, China. 
sub-basin of the Luan River watershed, which behaves as an ecological barrier of Tianjin and Beijing for the entire North China zone. The elevation varies between 663 and 1,814 m. The average slope is approximately $24 \%$ and the smallest slope is $20 \%$. Most of the watershed $(70 \%$ of the total area) is covered by forest, and agricultural land accounts for approximately $15 \%$. The main soil of the watershed is brown forest soil (approximately 75\%). The average annual precipitation is approximately $450 \mathrm{~mm}$, the average evaporation from the water surface is approximately $470 \mathrm{~mm}$, and the average annual runoff is approximately $16.9 \mathrm{~mm}$.

\section{Model description}

The hydrologic simulation program-FORTRAN (HSPF) model is a distributed, continuous, and lumped parameter watershed-scale model. It was developed to simulate water quantity and quality at any point in a watershed. It is composed of three application modules: PERLND, IMPLND, and RCHRES (Bicknell et al. 200I). The PERLND module simulates the hydrology and water quality processes for pervious land surfaces, IMPLND simulates the processes for impervious land surfaces, and RCHRES simulates the processes for streams and well-mixed lakes and reservoirs. In HSPF, a watershed is represented in terms of land segments and river reaches or reservoirs. Each land segment is referred to as a hydrologic response unit. Conceptually, runoff from the watershed moves laterally to a downslope segment or to a river reach/reservoir. HSPF uses simple storage-based (nonlinear reservoir) equations for flow routing
(Johnson et al. 2003). These equations consist of the spatially uniform and temporarily variable continuity equation and a flow equation expressed in terms of channel (or plane) roughness and geometry. For example, Manning's equation:

$$
\frac{\mathrm{d} s}{\mathrm{~d} t}=I-O
$$

and

$$
Q=\frac{1}{n} A^{5 / 3} R^{2 / 3} \sqrt{S_{0}}
$$

where $s$ is the storage volume of the water $\left(\mathrm{m}^{3}\right), t$ is the time step (s), $I$ is the inflow rate $\left(\mathrm{m}^{3} \mathrm{~s}^{-1}\right), O$ is the outflow rate $\left(\mathrm{m}^{3} \mathrm{~s}^{-1}\right), Q$ is the flow per unit width $\left(\mathrm{m}^{3} \mathrm{~s}^{-1} \mathrm{~m}^{-1}\right), n$ is Manning's roughness coefficient, $A$ is the flow cross-sectional area per unit width $\left(\mathrm{m}^{2} \mathrm{~m}^{-1}\right), R$ is the hydraulic radius $(\mathrm{m})$, and $S_{0}$ is the energy gradient $\left(\mathrm{m} \mathrm{m}^{-1}\right)$. Other processes simulated on the watershed include evapotranspiration (ET), interception, percolation, interflow, and groundwater movement. Channel routing is computed using storage or kinematic wave routing (Borah \& Bera 2003).

A detailed description of HSPF parameters is given in BASINS Technical Note 6 (US EPA 2000). The most sensitive parameters include INFILT, LZSN (lower zone storage nominal), upper zone storage nominal (UZSN), and INTFW, and represent the land surface hydrological processes of the PERLND module (Linsley et al. 1986). In this study, the model was calibrated by adjusting nine parameters (Table 1). These nine parameters represent

\begin{tabular}{|c|c|c|c|c|}
\hline Parameters & Definition & Unit & Range & Value \\
\hline LZSN & Lower zone nominal soil moisture storage & Inches & $2-15$ & 6.218 \\
\hline INFILT & Index to infiltration capacity & Inch/hour & $0.01-0.50$ & 0.108 \\
\hline AGWRC & Groundwater recession parameter & None & $0.85-0.999$ & 0.979 \\
\hline DEEPFR & Fraction of groundwater inflow to deep recharge & None & $1 \mathrm{E}-7-0.5$ & $1.60 \times 10^{-4}$ \\
\hline BASETP & Fraction of remaining evapotranspiration from baseflow & None & $0.01-0.2$ & $9.12 \times 10^{-2}$ \\
\hline AGWETP & Fraction of remaining evapotranspiration from active groundwater & None & $0.001-0.2$ & $4.73 \times 10^{-2}$ \\
\hline UZSN & Upper zone nominal soil moisture storage & Inches & $0.05-2.0$ & 2.000 \\
\hline INFTW & Interflow inflow parameter & None & $1.0-10$ & 8.344 \\
\hline IRC & Inflow recession parameter & None & $0.3-0.85$ & 0.850 \\
\hline
\end{tabular}

Table 1 | Parameters adjusted by PEST during calibration, based on hourly data from seven rain gauges 
HSPF model processes including interception, depression storage, infiltration, soil moisture storage, overland flow, interflow, and groundwater flow. The details of the nine parameters are given below.

LZSN is related to precipitation and soil characteristics in the watershed. Increasing the value of LZSN increases the amount of water stored in the lower zone and, therefore, increases the opportunity for evapotranspiration. This decreases flow rates by providing greater opportunity for evapotranspiration.

UZSN is related to land surface characteristics, topography, and LZSN. This parameter can change over the course of a growing season. Increasing UZSN increases the amount of water retained in the upper zone and available for evapotranspiration, allowing less overland flow.

INFILT is an index to mean soil infiltration rate. It is a function of soil characteristics and controls how much of the water from precipitation will become surface flow, subsurface flow, and a portion of the storage components. Increasing the value of INFILT produces more water in the lower zone and, therefore, generally results in higher base flow in the streams. Low values of INFILT will produce more upper zone and interflow storage water, resulting in greater direct overland flow (if the upper zone is saturated) and interflow.

AGWRC (analogous to the groundwater recession parameter) is the groundwater recession rate. It is the ratio of current groundwater discharge to that from 24 hours earlier when KVARY is zero. AGWRC is defined as the rate of flow today divided by the rate of flow yesterday.

INTFW is the coefficient that determines how much water will enter the ground from detention storage and become interflow (instead of direct overland flow and upper zone storage). INTFW has an effect on the timing of runoff by controlling the division of water between interflow and surface processes. Increasing the value of INTFW increases the amount of interflow, decreases direct overland flow and thereby reduces the peak flows while maintaining the same volume. It alters the shape of the hydrograph by shifting and delaying the flow to later in time. Decreasing INTFW has the opposite effect (raises the peaks). Base flow is not affected by INTFW. Once storm volumes have been calibrated, INTFW can be used to raise or lower peaks to match the observed hydrograph.

IRC is the interflow recession coefficient. It is AGWRC and is the ratio of current daily interflow to the interflow discharge on the previous day (24 hours earlier). IRC affects the rate at which interflow is discharged from storage, so it affects the shape of the hydrograph by altering the 'falling' phase (recession region) of the curve between the peak storm flow and baseflow.

DEEPFR is that fraction of the groundwater inflow which goes to inactive groundwater. The remaining portion of the percolating water plus all lateral inflow and/or irrigation application make up the total inflow to the active groundwater storage.

BASETP is the fraction of remaining potential ET that can be satisfied from baseflow (groundwater outflow), if enough is available.

AGWETP is the fraction of remaining potential ET that can be satisfied from active groundwater storage, if enough is available.

\section{Data collection and pretreatment}

Rainfall data were collected from the Chengde Branch of Hebei Provincial Survey Bureau of Hydrology and Water Resources, China. They included four temporal rainfall resolutions (hourly, 3-hourly, 12-hourly, and 24-hourly average rainfall) obtained from seven rain gauges between 2007 and 2009 (Figure 1). To study the impacts of temporal rainfall resolution on model accuracy and parameters, the hourly, 3-hourly, 12-hourly, and 24-hourly average rainfall data were input into the HSPF model and the data were disaggregated through the 'Changes interval' tool in WDMUtil (Bicknell et al. 20or). Additionally, we ran simulations using different amounts of rain gauges (1-7) to demonstrate the effects of spatial rainfall resolution on the model accuracy and parameters. To achieve this, the rain gauges were excluded one by one according to the controlled minimum area calculated using Thiessen polygons (Lopes I996). 
The Digital Elevation Model $(1: 24,000)$ for the watershed was downloaded from the International Scientific Data Service Platform, Chinese Academy of Science. The land use data were obtained using Spot5 imagery with $20 \mathrm{~m}$ resolution for the year 2007, and were acquired from the Data Sharing Infrastructure of Earth System Science. Soil data $(1: 1,000,000)$ were downloaded from the Data Center for Resources and Environmental Sciences, Chinese Academy of Sciences. The measured daily runoffs of the watershed outlet were collected between 2007 and 2009 from the Chengde Branch of Hebei Provincial Survey Bureau of Hydrology and Water Resources. Meteorological data (evaporation, temperature, wind speed, etc.) were collected from the China Meteorological Data Sharing Service System.

\section{Model calibration}

Two calibration approaches are commonly used for HSPF, the manual calibration tool (HSPEXP) (Lumb et al. 1994) and automatic PEST (Doherty 200I). Manual calibrations are time-consuming and tedious (Madsen 2000), and only offer parameter adjustment guidance to model users. However, PEST automatic calibration is less subjective, faster, and more efficient than HSPEXP-assisted manual calibrations. Additionally, several studies have demonstrated that PEST can be used to calibrate a HSPF model (Kim et al. 2007; Ryu 2009). Therefore, we used PEST to calibrate the HSPF model in this study.

The HSPF model parameters that affect the runoff of Yixun River were calibrated using the measured daily runoff data from 2007 to 2009. Since there is a lack of better guidance for parameter selection, we assumed that the parameter values with the best performance should be closer to the 'true' but unknown parameter values of the watershed. We evaluated the model using observed data from the watershed outlet. The objective functions used in the model calibration were the coefficient of determination $\left(R^{2}\right)$, Nash-Sutcliffe coefficient (NSE), and relative error $(R E)$. They are defined as

$$
R^{2}=\frac{\sum_{i=1}^{n}\left(y_{\mathrm{sim}}^{i}-\bar{y}_{\mathrm{sim}}\right) \cdot\left(y_{\mathrm{obs}}^{i}-\bar{y}_{\mathrm{obs}}\right)}{\sum_{i=1}^{n}\left(y_{\mathrm{sim}}^{i}-\bar{y}_{\mathrm{sim}}\right)^{2} \cdot \sum_{i=1}^{n}\left(y_{\mathrm{obs}}^{i}-\bar{y}_{\mathrm{obs}}\right)^{2}},
$$

$$
N S E=1-\frac{\sum_{i=1}^{n}\left(y_{\text {sim }}^{i}-y_{\mathrm{obs}}^{i}\right)^{2}}{\sum_{i=1}^{n}\left(y_{\mathrm{sim}}^{i}-\bar{y}_{\mathrm{obs}}\right)^{2}},
$$

and

$$
R E=\frac{\sum_{i=1}^{n}\left(y_{\mathrm{sim}}^{i}-y_{\mathrm{obs}}^{i}\right)}{\sum_{i=1}^{n} y_{\mathrm{obs}}^{i}} \times 100 \%,
$$

where $y_{\text {sim }}^{i}$ is the daily simulated runoff on day $i, y_{\mathrm{obs}}^{i}$ is the daily observed runoff on day $i, \bar{y}_{\mathrm{obs}}$ is the average observed runoff over the simulated period, and $\bar{y}_{\text {sim }}$ is the average simulated runoff over the simulated period.

\section{Assessment method}

We used the static sensitivity method (Andréassian et al. 2004) to assess the impacts of rainfall resolution on model accuracy. First, we obtained an optimal group of parameters using the 'perfect' resolution inputs (hourly rainfall data from seven rain gauges). We then fixed these parameters and compared the values of $R^{2}, N S E$, and $R E$ obtained using 'erroneous' temporal and spatial resolution rainfall data. Finally, we analyzed the significance of the differences in the runoff simulated by the 'erroneous' and 'perfect' parameters using the paired-samples $t$-test method. We ran this test using SPSS 16.0 for Windows (SPSS Inc., Chicago, IL).

We used the dynamic sensitivity method (Andréassian et al. 2004) to assess the impacts of rainfall resolution on the model parameters. First, we calculated the optimal parameters by calibrating the model using data with different resolutions. Then, we compared the different parameter values. Finally, we used the standard deviation, variance, range (the gap between the maximum and the minimum), and standard error of the mean to analyze how the model parameters changed in response to different temporal and spatial rainfall resolutions.

Note that the spatial resolution was kept constant (seven rain gauges) when investigating the effects of temporal resolution on the HSPF modeled runoff. The temporal resolution was kept constant (hourly resolution) when investigating the effects of the spatial resolution. 


\section{RESULTS}

\section{Model performance}

The results of the daily runoff calibration for the period 2007-2009 using the finest temporal and spatial rainfall resolution (hourly data from seven rain gauges) are shown in Figure 2. The simulated flow had an annual pattern that was similar to the observed values. It is characterized by a low volume in winter and a high volume in summer. The values of $R^{2}, N S E$, and $R E$ for the simulated daily runoff were $0.81,0.80$, and $-11.1 \%$, respectively. These results indicate that the simulated flow was a close fit to the observed values. The period between 2010 and 2011 was used to validate the model, although the focus of this study was model calibration. The values of $R^{2}, N S E$, and $R E$ for the simulated daily runoff during the validation period were $0.78 \%, 0.72 \%$, and $-8.5 \%$, respectively.

The parameters listed in Table 1 represent the optimal calibrated parameters based on the hourly data from all

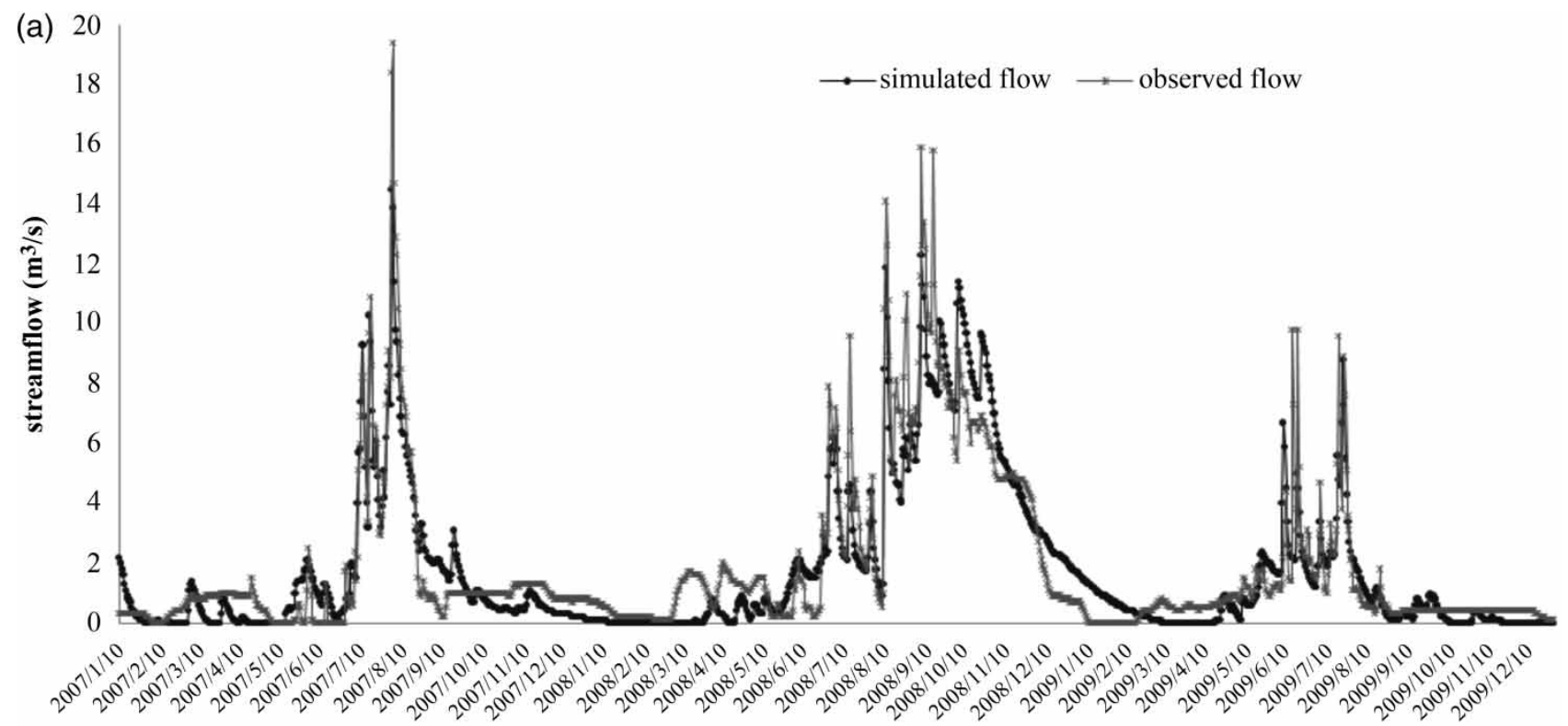

(b)

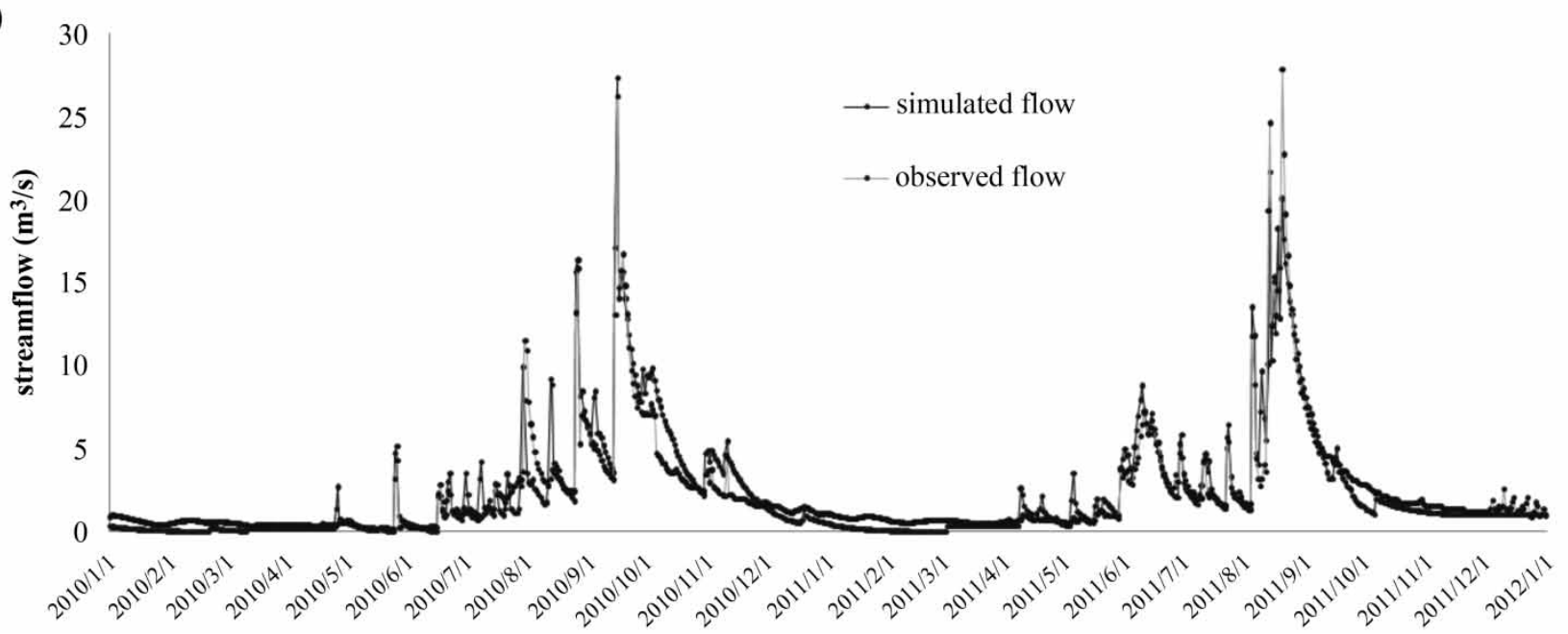

Figure 2 | Calibration of the daily runoff from 2007 to 2009 (a) and validation of the daily runoff from 2010 to 2011 (b). The calibration and validation were based on hourly data from seven rain gauges. 

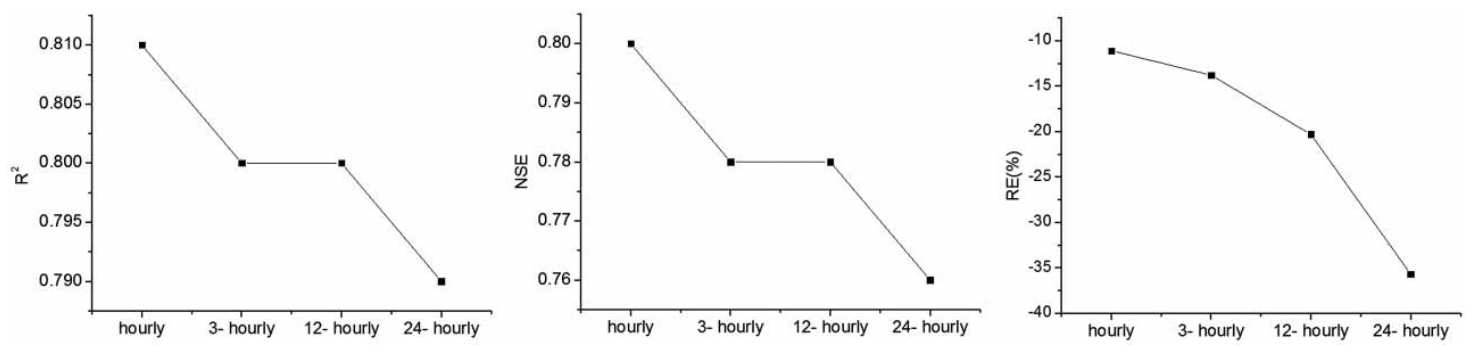

Figure 3 Model performance for the daily runoff analysis using hourly, 3-hourly, 12-hourly, and 24-hourly rainfall data.

seven rain gauges. The parameter values determined by calibrating the HSPF model vary with the rainfall input data. In most cases, the parameter values do not reflect measurable basin characteristics such as the topography, vegetation, soil, and channel network. In this study, we hypothesize that the rainfall resolution is a major source of equifinality. Therefore, this study investigated whether equifinality could be reduced by the appropriate rainfall resolution, and if we could estimate parameters that had some physical significance.

\section{Effect of rainfall temporal resolution on model accuracy}

In this study, we investigated the effect of four different temporal resolutions on the model accuracy. We considered hourly, 3-hourly, 12-hourly, and 24-hourly rainfall input data. We used the parameters adjusted by PEST during the calibration based on hourly data from seven rain gauges (Table 1). The model simulated the daily runoff using these four temporal resolutions. The runoff time series modeled using the hourly, 3-hourly, 12-hourly, and 24-hourly data were defined as T1, T3, T12, and T24. The model accuracies are shown in Figure 3. There was an insignificant decrease in $R^{2}$ and NSE when the temporal resolution became coarse. The $R^{2}$ values of the runoff calculated using hourly, 3-hourly, 12-hourly, and 24-hourly rainfall data were $0.81,0.78,0.78$, and 0.76 , respectively. The NSEs of the runoff calculated using hourly, 3-hourly, 12hourly, and 24-hourly rainfall data were 0.80, 0.77, 0.77, and 0.74 , respectively. By contrast, the average daily REs of the runoff calculated using hourly, 3-hourly, 12-hourly, and 24-hourly rainfall data decreased sharply, and were $-11.1 \%,-13.8 \%,-20.3 \%$, and $-35.7 \%$, respectively.

One of the aims of this study was to analyze the extent that the data resolution affects the accuracy of the model.
The paired-samples $t$-test can compare different time series extracted from runs that used different resolutions of rainfall and assess whether the differences are significant. Here, the $\mathrm{T} 1$ time series is considered as optimal. We compared T3 and T1, T12 and T1, T24 and T1, as shown in Table 2. The values of sig (2-tailed) were less than 0.001, which revealed there were significant differences between the compared time series. That is, while holding the other parameters constant, the different temporal resolutions had an obvious and significant impact on the HSPF model.

\section{Effect of rainfall temporal resolution on model parameters}

In this section, we analyzed the differences in the parameters when the model was calibrated with data at the four different temporal resolutions, to better understand the model behavior. Figure 4 shows the parameters' values for the HSPF model. The model accuracy changed when the model was recalibrated using the four different temporal resolutions. The values of $R^{2}$ of the runoff calculated using hourly, 3-hourly, 12-hourly, and 24-hourly rainfall data were $0.81,0.80,0.80$, and 0.79 , the NSEs were $0.80,0.78,0.78$, and 0.76 , and the REs were $-11.1 \%,-13.1 \%,-18.4 \%$, and $-31.8 \%$, respectively.

Another aim of this study was to investigate how the model parameters change when using different temporal and spatial

Table 2 | Paired-samples $t$-test of the daily runoffs using the T1 (hourly), T3 (3-hourly), T12 (12-hourly), and T24 (daily) time series

\begin{tabular}{llll} 
Runoff time series & Std deviation & std error of mean & Sig (2-tail) \\
\hline T1-T3 & 0.14 & 0.004 & 0.000 \\
T1-T12 & 0.27 & 0.008 & 0.000 \\
T1-T24 & 0.68 & 0.021 & 0.000 \\
\hline
\end{tabular}



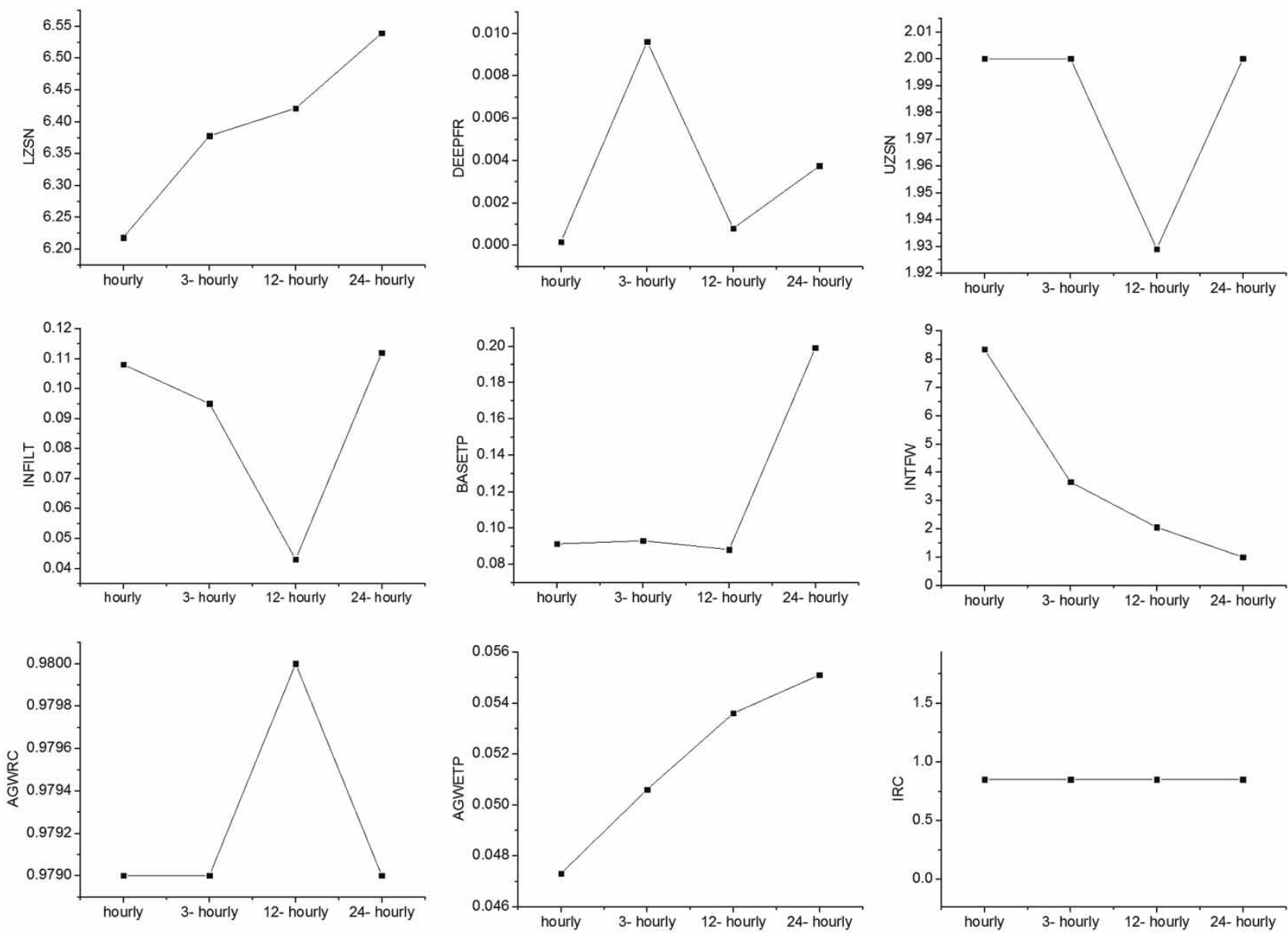

Figure 4 | Comparison of model parameters in the daily runoff analysis using hourly, 3-hourly, 12-hourly, and 24-hourly rainfall data.

rainfall resolutions. We analyzed the differences in the parameters, and the statistics are shown in Table 3. We can see that the most significant differences were in INTFW. Figure 4

Table 3 | Statistical analysis of the parameters resulting from four different temporal resolutions

\begin{tabular}{lllrll} 
Parameters & Mean & Range & variance & $\begin{array}{l}\text { Std } \\
\text { deviation }\end{array}$ & $\begin{array}{l}\text { Std error of } \\
\text { mean }\end{array}$ \\
\hline LZSN & 6.3890 & 0.3210 & 0.0176 & 0.1328 & 0.0664 \\
INFILT & 0.0895 & 0.0690 & 0.0010 & 0.0318 & 0.0159 \\
AGWRC & 0.9793 & 0.0010 & 0.0000 & 0.0005 & 0.0002 \\
DEEPFR & 0.0036 & 0.0094 & 0.0000 & 0.0043 & 0.0022 \\
BASETP & 0.1178 & 0.1109 & 0.0029 & 0.0542 & 0.0271 \\
AGWETP & 0.0517 & 0.0078 & 0.0000 & 0.0035 & 0.0017 \\
UZSN & 1.9823 & 0.0710 & 0.0013 & 0.0355 & 0.0178 \\
INTFW & 3.7638 & 7.3440 & 10.5119 & 3.2422 & 1.6211 \\
IRC & 0.8500 & 0.0000 & 0.0000 & 0.0000 & 0.0000 \\
\hline
\end{tabular}

shows that most of the model parameters were changed. The parameter of IRC achieved the max value (0.85) in all resolution scenarios. However, Table 3 shows that the variation trend and range of the parameters were different, which implies that the model parameters were affected by the temporal resolution of the rainfall input. These physical interpretations are analyzed in the following discussion.

\section{Effect of rainfall spatial resolution on model efficiency}

In these experiments, we used the parameters adjusted by PEST during a calibration based on hourly data from seven rain gauges. We then adjusted the model so that it used between one and six rain gauges. The runoff time series modeled using these seven resolutions were defined as S7, S6, S5, S4, S3, S2, and S1. Figure 5 shows a comparison of the accuracies of S7-S1. For all spatial resolutions, $R^{2}$ ranged from 

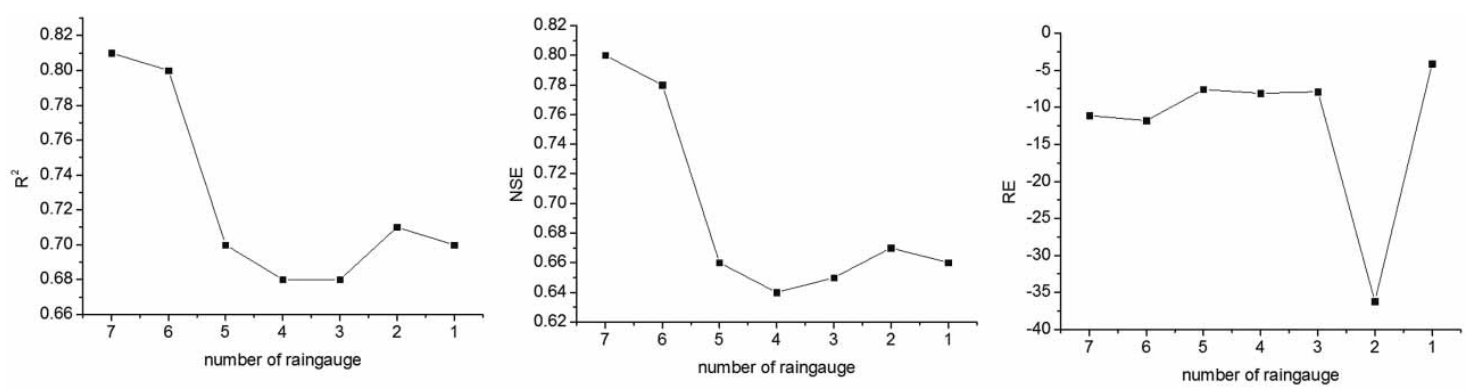

Figure 5 | Model performances for the daily runoff analysis using different spatial resolutions of rainfall data.

0.62 to 0.81 , NSE ranged from 0.49 to 0.80 , and $R E$ ranged from $-36.2 \%$ to $-4.1 \%$. There was a small decrease in $R^{2}$ and NSE as the spatial resolution became coarser. $R^{2}$ and $N S E$ had significant decreases when going from six to five rain gauges, and from two to one rain gauge. This indicated that the model's performance was affected by the spatial resolution of the rainfall data. In particular, a coarse spatial resolution can be very detrimental to the model accuracy.

We used the paired-samples $t$-test to compare S6 and S7, S5 and S7, S4 and S7, S3 and S7, S2 and S7, and S1 and S7. The results are shown in Table 4. The values of sig (2-tailed) indicated that the differences between S6 and S7, S5 and S7, S4 and S7, and S3 and S7 were not significant, but the differences between S2 and S7, S1 and S7 were significant.

\section{Effect of rainfall spatial resolution on the model parameters}

Figure 6 shows comparisons of the PEST estimated parameter values using different spatial resolutions of rainfall input (the number of rain gauges represents the resolution). The spatial redistribution of the rainfall data causes the parameters' values to change so that they achieve the best

Table 4 | Paired-samples $t$-test of the daily runoff analyses S7 (seven gauges), S6 (six gauges), S5 (five gauges), S4 (four gauges), S3 (three gauges), S2 (two gauges), and S1 (one gauge)

\begin{tabular}{llll} 
& Std deviation & Std error of mean & Sig (2-tail) \\
\hline S7-S6 & 0.35 & 0.01 & 0.188 \\
S7-S5 & 1.01 & 0.03 & 0.006 \\
S7-S4 & 1.09 & 0.03 & 0.023 \\
S7-S3 & 1.04 & 0.03 & 0.011 \\
S7-S2 & 1.05 & 0.03 & 0.000 \\
S7-S1 & 1.44 & 0.04 & 0.000 \\
\hline
\end{tabular}

model accuracy. After recalibrating the model, the $R^{2}$ values for the runoff calculated using 7-1 rain gauges were $0.80,0.78,0.66,0.64,0.65,0.67$, and 0.66 , and the NSEIs were $0.81,0.80,0.70,0.68,0.68,0.71$, and 0.70 . Note that there were significant changes to many of the parameters when using the two rain gauges' resolution, which may be because its $R E$ was the most significant in Figure 6.

We analyzed the changes to the parameters that were caused by different spatial resolutions, as shown in Table 5. There were significant changes to INTFW, LZSN, and BASETP. This indicates that the effect of the spatial rainfall resolution was greater than that of the temporal resolution, because there were only significant changes to INTFW for different temporal resolutions.

\section{Effect of the location of the rainfall gauges on the HSPF model performance and parameters}

To explore the response of the catchment when excluding rain gauges at different locations (upper, middle, and lower reach), we investigated the effect of the location of one rainfall gauge on the HSPF model performance and parameters. Using the parameters adjusted by PEST during the calibration based on hourly data from seven rain gauges, we calculated the model simulated runoff using only one rainfall gauge (the name of rainfall gauge is shown in Figure 1). We compared the performances of these different models, as shown in Figure 7. Using seven rainfall gauge scenarios, $R^{2}$ ranged from 0.51 to 0.74 , and NSE ranged from 0.32 to 0.62 . From Figure 7 , it is shown that the model accuracy was relatively high in the ZSY, WC, and HQ stations, but on the other hand, in the BJT and QPS stations, the model accuracy was relatively low. This indicated that when the rainfall gauge is located in the middle or downstream, the model performs better. 

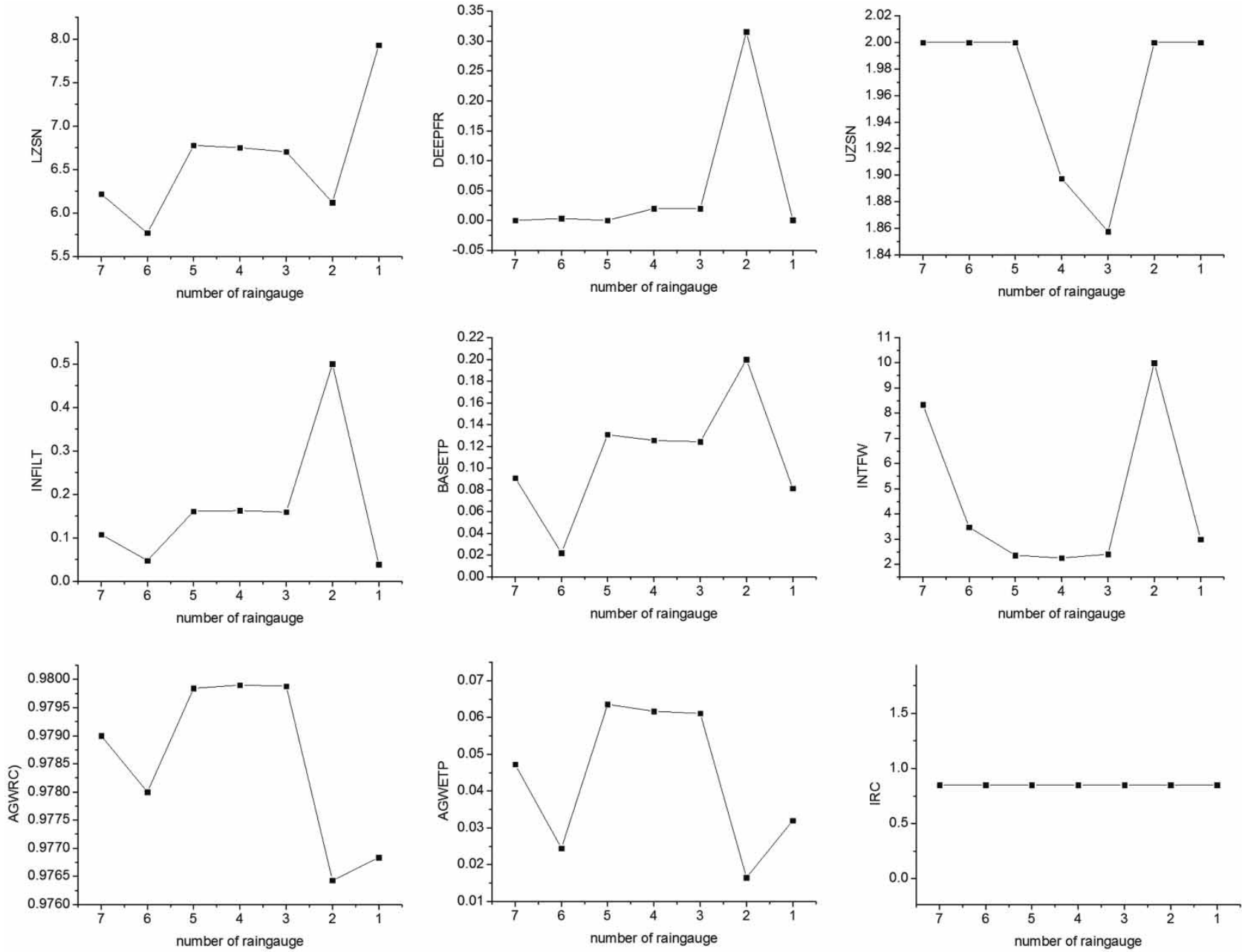

Figure 6 | Comparison of the model parameters in the daily runoff analysis using different spatial resolutions of rainfall data (represented by the number of rain gauges).

Table 5 | Statistical analysis of the parameters using seven different spatial resolutions

\begin{tabular}{lllrll} 
Parameter & Mean & Range & variance & $\begin{array}{l}\text { Std } \\
\text { deviation }\end{array}$ & $\begin{array}{l}\text { Std error of } \\
\text { mean }\end{array}$ \\
\hline LZSN & 6.6099 & 2.1607 & 0.4832 & 0.6951 & 0.2627 \\
INFILT & 0.1682 & 0.4612 & 0.0242 & 0.1555 & 0.0588 \\
AGWRC & 0.9786 & 0.0035 & 0.0000 & 0.0015 & 0.0006 \\
DEEPFR & 0.0514 & 0.3155 & 0.0137 & 0.1169 & 0.0442 \\
BASETP & 0.4233 & 2.1287 & 0.6222 & 0.7888 & 0.2981 \\
AGWETP & 0.0438 & 0.0471 & 0.0004 & 0.0195 & 0.0074 \\
UZSN & 1.9650 & 0.1424 & 0.0037 & 0.0608 & 0.0230 \\
INTFW & 4.5460 & 7.7529 & 10.3968 & 3.2244 & 1.2187 \\
IRC & 0.8500 & 0.0000 & 0.0000 & 0.0000 & 0.0000 \\
\hline
\end{tabular}

The model parameters changed when we recalibrated the model using these seven rainfall gauge scenarios, as shown in Figure 8. Our analysis of the changes to the parameters caused by the location of the rainfall data is shown in Table 6.

We analyzed the changes to the parameters that were caused by the location of the rainfall gauges, as shown in Table 6. There were three parameters that changed significantly and these were LZSN, INTFW, and UZSN. This indicates that the effect of the location of the rainfall gauges was similar to the resolution of rainfall data, and that LZSN and INTFW were the parameters that changed significantly. 

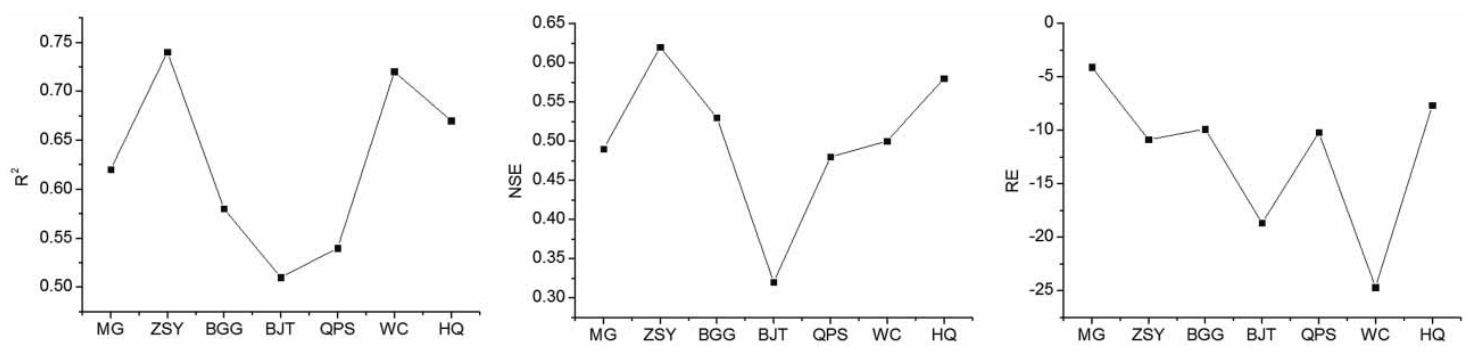

Figure 7 | Model performances for daily runoff analysis using different locations of rainfall gauges.
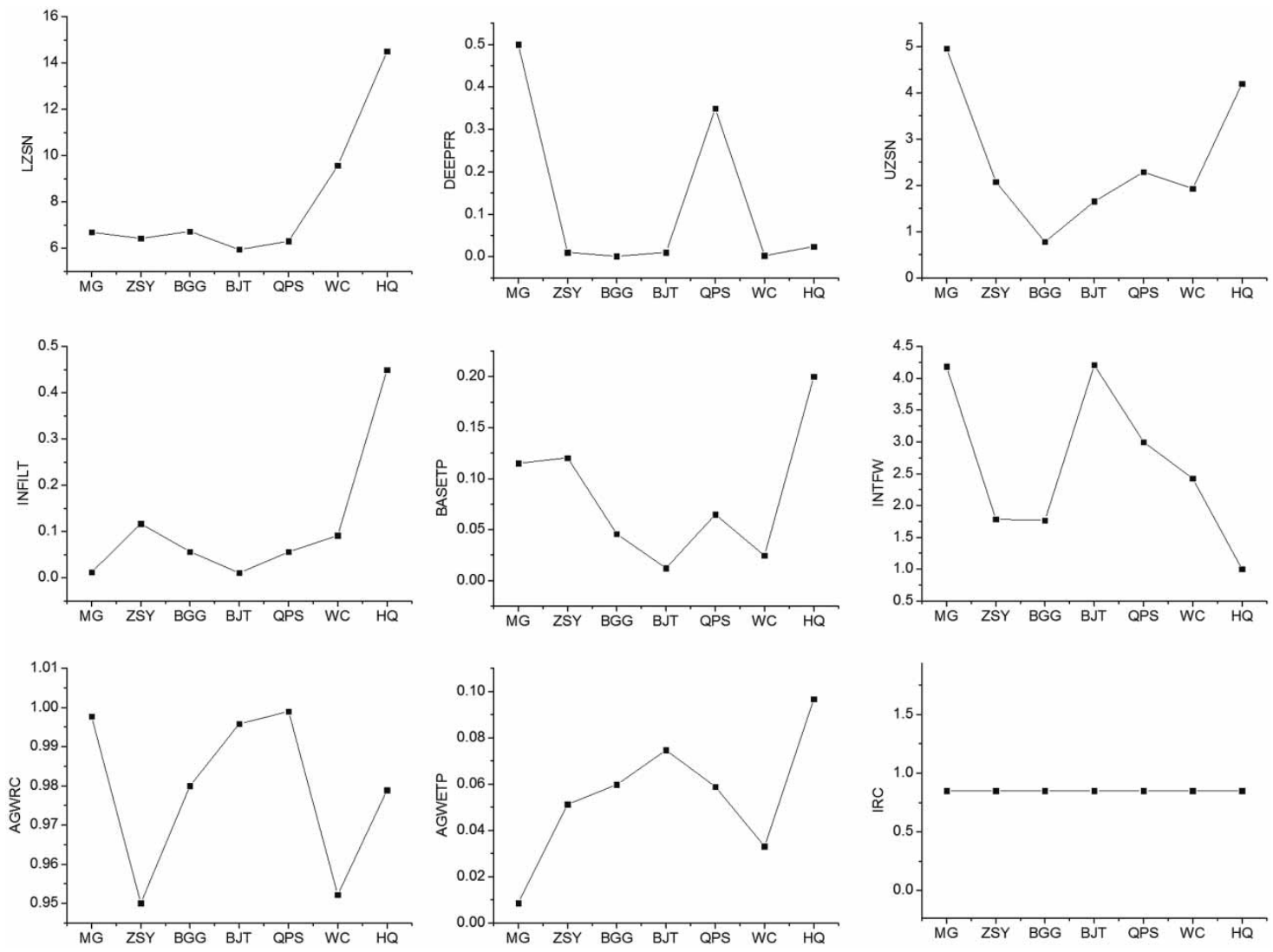

Figure 8 | Comparison of the model parameters in the daily runoff analysis using different location rainfall data.

\section{DISCUSSION}

\section{Effect of temporal and spatial rainfall resolution on HSPF model performance}

One of the objectives of this study was to examine the impact of temporal and spatial rainfall resolution on the accuracy and parameters of the HSPF modeled runoff. We found that the accuracy was affected by both the temporal and spatial resolution when the other parameters were constant (Figures 3 and 5). The rainfall resolution had a strong influence on the PEST (Figures 4 and 6). This is because the parameter values must change when the resolution of the rainfall data change. The HSPF models use their 
Table 6 Statistic analysis for the parameters adjusted by different location rainfall data

\begin{tabular}{llllll} 
Parameter & Mean & Range & variance & $\begin{array}{l}\text { Std } \\
\text { deviation }\end{array}$ & $\begin{array}{l}\text { Std error of } \\
\text { mean }\end{array}$ \\
\hline LZSN & 8.0267 & 8.5666 & 9.6182 & 3.1013 & 1.1722 \\
INFILT & 0.1133 & 0.4390 & 0.0235 & 0.1533 & 0.0579 \\
AGWRC & 0.9791 & 0.0489 & 0.0004 & 0.0208 & 0.0078 \\
DEEPFR & 0.1283 & 0.4987 & 0.0430 & 0.2073 & 0.0783 \\
BASETP & 0.0832 & 0.1879 & 0.0044 & 0.0662 & 0.0250 \\
AGWETP & 0.0547 & 0.0881 & 0.0008 & 0.0283 & 0.0107 \\
UZSN & 2.5537 & 4.1759 & 2.1843 & 1.4779 & 0.5586 \\
INTFW & 2.6235 & 3.2100 & 1.5355 & 1.2392 & 0.4684 \\
IRC & 0.8500 & 0.0000 & 0.0000 & 0.0000 & 0.0000 \\
\hline
\end{tabular}

corresponding parameters to absorb various resolutions of rainfall data and mitigate their impact on the runoff simulations. When the model was calibrated using different temporal resolutions of rainfall data, the most significant changes were to INTFW. When the model was calibrated using different spatial resolutions, there were obvious changes to LZSN and BASETP but the most significant changes were to INTFW. We discuss why there were significant changes to these parameters in the next section, when we consider the physical interpretation. In this study, we analyzed the differences of the average runoffs in the calibrated period. However, the disaggregation of readily available 3-hourly, 12-hourly, or 24-hourly rainfall to hourly rainfall resulted in a rainfall intensity anamorphosis. This may lead to poor peak flow predictions and consequently reduce the model performance. Thus, the effect of the rainfall resolution on model accuracy in different seasons must be considered in the future, especially in watersheds where the rainfall has a high seasonal variability. For example, in China, there are many watersheds where more than $70 \%$ of the annual precipitation occurs between July and September.

Another objective of this study was to examine to what extent these effects depend on their temporal and spatial resolutions. In this paper, we used a statistical analysis to answer this question. The paired-samples $t$-test compares the means of two variables in a single group. The method computes the differences between the values of the two variables in each case and tests whether the average differs from 0 . However, it cannot reflect whether there are significant differences in the peak or trough flows. We must consider more statistical analysis techniques in the future so that we can identify these differences.

\section{How the model parameters change according to different temporal and spatial rainfall resolutions}

If the rainfall input is different, the model will change. This is especially true for changes to the time and space resolutions of the rainfall. The rainfall intensity and moisture changes the hydrological segment of the HSPF calculation, and thus, the water balance is redistributed. When the moisture supplied by the rainfall exceeds the interception capacity, it falls on the surface of the land. Then it may infiltrate, go to the upper zone or interflow storage, remain in surface detention storage, or run off. Figure 9 represents the infiltration/interflow/surface runoff distribution function of PWATER.

The infiltration distribution is focused around the two lines that separate the moisture available to the land surface (MSUPY) into what infiltrates and what goes to interflow. The quantity under Line I is considered to be infiltrated. The amount over the line but under the MSUPY line (the entire shaded portion) is the potential direct runoff (PDRO, combined increment to the interflow), the upper zone storage, and the quantities that will stay on the surface and run off. PDRO is subdivided by Line II. The ordinates of Line II are found by multiplying the ordinates of Line I by ratio of the ordinates (RATIO) of Line II to Line I). The quantity underneath Line II and the MSUPY line but above Line I is called the potential interflow inflow. This consists of the actual interflow plus an increment to the

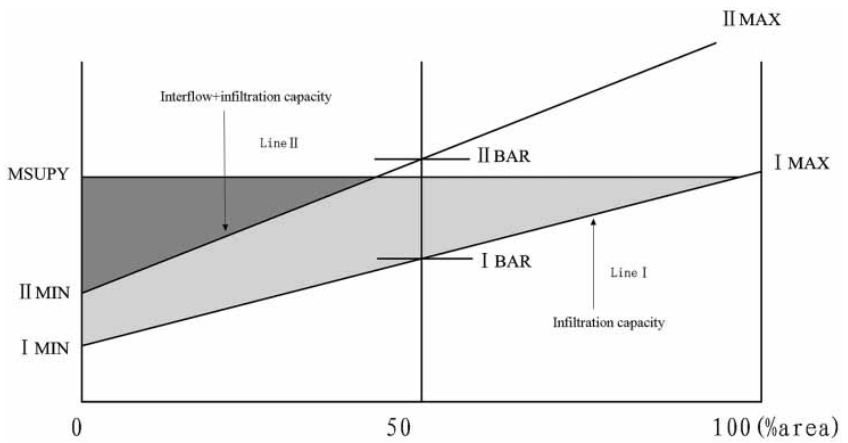

Figure 9 | Determination of infiltration and interflow inflow. 
upper zone storage. Any amount above Line II but below the MSUPY (potential surface detention/runoff) is that portion of the moisture supply that stays on the surface and is available for overland flow routing, plus a further increment to the upper zone storage.

Because details of the short duration high-intensity rainfall events are lost through temporal aggregation and spatial interpolation of the rainfall data, the runoff generation process nonlinearities are not captured properly. In this study, the disaggregation of readily available 3-hourly, 12-hourly, or 24-hourly rainfall to hourly rainfall for an HSPF model using the WDMUtil tool in BASINS preserves the daily rainfall depth. However, it does not accurately reproduce the temporal distribution of the observed rainfall intensity at an hourly resolution. The spatial resolution of the rainfall data changes the rainfall depth of the hydrological calculation unit. From the runoff distribution function in HSPF, we can see that MSUPY and RATIO are important and decide how much moisture infiltrates or becomes potential direct runoff. MSUPY is the MSUPY, which is closely related to the rainfall intensity and depth. Thus, when the rainfall intensity or depth changes, the runoff distribution in HSPF will adjust RATIO (RATIO of Line II to Line I). This is defined as

$R A T I O=I N T F W * 2^{L Z S / L Z S N}$

where $R A T I O$ is the ratio of the ordinates of Line II to Line I, INTFW is interflow inflow parameter, LZS is the lower zone storage (inches), and LZSN is a parameter for the lower zone nominal storage (inches).

That is, to achieve a high model performance, the parameters must change when the resolution of the rainfall data changes, especially the parameters that determine the runoff distribution in HSPF.

\section{CONCLUSION}

Our results highlighted the effects of temporal and spatial rainfall resolutions on the accuracy and parameters of the HSPF modeled runoff. We demonstrated the discriminative power of the comparative statistics when describing the effects of the rainfall data's resolution on HSPF modeled runoff. Fine temporal and spatial rainfall resolutions achieve a better model performance. When holding the parameters constant, the model performance was more sensitive to the temporal resolution than the spatial resolution. When the resolution of the rainfall data changed, the parameter values must be changed to maintain a high model performance. INTFW, LZSN, and BASETP were the most sensitive to the rainfall resolution. Our results indicate that we must attempt to collect rainfall data at a fine resolution to minimize the uncertainties in the model simulations, especially for large watersheds.

\section{ACKNOWLEDGEMENTS}

Funding was supported by the Key Research Program of the Chinese Academy of Sciences (No. KZZD-EW-10-02-3), and Water Pollution Control and Treatment of National Science and Technology Major Project in China (No. 2014ZX07203010). The authors would like to thank the Chengde Branch of Hebei Provincial Survey Bureau of Hydrology and Water Resources for providing hydrological data. Finally, the authors would like to express their sincere gratitude to the anonymous reviewers for their constructive comments and the Editor of the journal. Their detailed suggestions have resulted in an improved manuscript.

\section{REFERENCES}

Adams, R., Western, A. W. \& Seed, A. W. 2012 An analysis of the impact of spatial variability in rainfall on runoff and sediment predictions from a distributed model. Hydrol. Process. 26, 3263-3280.

Andréassian, V., Perrin, C. \& Michel, C. 2004 Impact of imperfect potential evapotranspiration knowledge on the efficiency and parameters of watershed models. J. Hydrol. 235, 19-35.

Aronica, G., Freni, G. \& Oliveri, E. 2005 Uncertainty analysis of the influence of rainfall time resolution in the modelling of urban drainage systems. Hydrol. Process. 19, 1055-1071.

Beven, K. J. 200I Rainfall-Runoff Modelling. John Wiley \& Sons, Ltd, Chichester, UK, 360 pp.

Bicknell, B. R., Imhoff, J. C., Kittle, J. L., Jobes, T. H. \& Donigian, A. S. 200I Hydrological Simulation Program - FORTRAN (HSPF). User's Manual for Release 12. US EPA Environmental Research Laboratory, Athens, GA, in cooperation with US Geological Survey, Office of Surface Water, Reston, VA. 
Borah, D. K. \& Bera, M. 2003 Watershed-scale hydrologic and nonpoint-source pollution models: Review of mathematical bases. Trans. ASABE 46 (6), 1553-1566.

Doherty, J. 200I PEST-ASP User's Manual. Watermark Numerical Computing, Brisbane, Australia.

Duncan, M., Austin, B., Fabry, F. \& Austin, G. 1993 The effect of gauge sampling density on the accuracy of streamflow prediction for rural catchments. J. Hydrol. 142, 445-476.

Finnerty, B. D., Smith, M. B., Seo, D. J., Koren, V. \& Moglen, G. E. 1997 Space-time scale sensitivity of the Sacramento model to radar-gage precipitation inputs. J. Hydrol. 203 (1-4), 21-38.

Johnson, M. S., Coon, W. F., Mehta, V. K., Steenhuis, T. S., Brooks, E. S. \& Boll, J. 2003 Application of two hydrologic models with different runoff mechanisms to a hillslope dominated watershed in the northeastern US: a comparison of HSPF and SMR. J. Hydrol. 284 (1-4), 57-76.

Kim, S. M., Benham, B. L., Brannan, K. M., Zeckoski, R. W. \& Doherty, J. 2007 Comparison of hydrologic calibration of HSPF using automatic and manual methods. Water Resour. Res. 43, W01402.

Krajewski, W. F., Lakshmi, V., Georgakakos, K. P. \& Jain, S. C. I99I A Monte Carlo study of a distributed catchment model. Water Resour. Res. 27 (1), 119-128.

Linsley, R. K., Kohler, M. A. \& Paulhus, J. L. H. 1986 Hydrology for Engineers. McGraw-Hill, New York.

Littlewood, I. G. \& Croke, B. F. W. 2008 Data time-step dependency of conceptual rainfall-streamflow model parameters: an empirical study with implications for regionalisation. Hydrol. Sci. J. 53 (4), 685-695.

Littlewood, I. G. \& Croke, B. F. W. 2013 Effects of data time-step on the accuracy of calibrated rainfall-streamflow model parameters: practical aspects of uncertainty reduction. Hydro. Res. 44 (3), 430-440.

Littlewood, I. G., Croke, B. F. W. \& Young, P. C. 201 Discussion of 'Effects of temporal resolution on hydrological model parameters and its impact on prediction of river discharge'. Hydrol. Sci. J. 56 (3), 521-524.

Lopes, V. L. 1996 On the effect of uncertainty in spatial distribution of rainfall on catchment modeling. Catena 28, 107-119.

Lumb, A. M., Mccammon, R. B. \& Kittle, J. L. 1994 Users Manual for an Expert System (HSPEXP) for Calibration of the
Hydrological Simulation Program FORTRAN. US Geological Survey, Reston, VA.

Madsen, H. 2000 Automatic calibration of a conceptual rainfallrunoff model using multiple objectives. J. Hydrol. 235 (3-4), 276-288.

Mohamoud, Y. M. \& Lourdes, M. P. 2012 Effect of temporal and spatial rainfall resolution on HSPF predictive performance and parameter estimation. J. Hydrol. Eng. 17, 377-388.

Oudin, L., Perrin, C., Mathevet, T., Andréassian, V. \& Michel, C. 2006 Impact of biased and randomly corrupted inputs on the efficiency and the parameters of watershed models. J. Hydrol. 320, 62-83.

Paturel, J. E., Servat, E. \& Vassiliadis, A. 1995 Sensitivity of conceptual rainfall-runoff algorithms to errors in input datacase of the GR2M model. J. Hydrol. 168, 111-125.

Pechlivanidis, I. G., McIntyre, N. R. \& Wheater, H. S. 2010 Calibration of the semi-distributed PDM rainfall-runoff model in the Upper Lee catchment, UK. J. Hydrol. 386, 198-209.

Pechlivanidis, I. G., Jackson, B., McIntyre, N. \& Wheater, H. S. 2oII Catchment scale hydrological modelling: A review of model types, calibration approaches and uncertainty analysis methods in the context of recent developments in technology and applications. Global NEST J. 13 (3), 193-214.

Ryu, J. H. 2009 Application of HSPF to the distributed model intercomparison project: Case study. J. Hydrol. Eng. 14 (8), 847-857.

Segond, M. L., Wheater, H. S. \& Onof, C. 2007 The significance of spatial rainfall representation for flood runoff estimation: A numerical evaluation based on the Lee Catchment, UK. J. Hydrol. 347 (1-2), 116-131.

Sun, X. R. G., Mein, R. G., Keenan, T. D. \& Elliott, J. F. 2000 Flood estimation using radar and raingauge data. J. Hydrol. 239 (1-4), 4-18.

US Environmental Protection Agency 2000 EPA BASINS Technical Note 6: Estimating hydrology and hydraulic parameters for HSPF. EPA-823 R00-012. US EPA Office of Water, Washington, DC.

Wang, Y., He, B. \& Takase, K. 2009 Effects of temporal resolution on hydrological model parameters and its impact on prediction of river discharge. Hydrol. Sci. J. 54 (5), 886-898.

Xu, C. Y. \& Vandewiele, G. L. 1994 Sensitivity of monthly rainfall runoff models to input errors and data length. Hydrol. Sci. J. 39 (2), 157-176.

First received 24 October 2013; accepted in revised form 13 September 2014. Available online 14 October 2014 